\title{
Cardiorespiratory Fitness, Health-Related Physical Fitness and Academic Performance in College Students
}

\author{
Chung Bing Yang1, Te Hung Tsao ${ }^{2 *}$ \\ ${ }^{1}$ Department of Physical Education and Kinesiology, National Dong Hwa University, Taiwan, China \\ ${ }^{2}$ The Center for Physical and Health Education, National Sun Yat-Sen University, Taiwan, China \\ Email: *thtsao@mai.nsysu.edu.tw, t1208t2001@gmail.com
}

How to cite this paper: Yang, C. B., \& Tsao, T. H. (2020). Cardiorespiratory Fitness, Health-Related Physical Fitness and Academic Performance in College Students. Advances in Physical Education, 10, 42-53. https://doi.org/10.4236/ape.2020.101005

Received: January 10, 2020

Accepted: February 11, 2020

Published: February 14, 2020

Copyright $\odot 2020$ by author(s) and Scientific Research Publishing Inc. This work is licensed under the Creative Commons Attribution International License (CC BY 4.0).

http://creativecommons.org/licenses/by/4.0/

\begin{abstract}
Whether cardiorespiratory fitness (CRF) and physical fitness affect academic performance in college first-year students is a concerning issue. Therefore, the goal of this study was to examine the relationship between academic performance and CRF and the components of physical fitness in college first-year students. A total of 98 college first-year students (female: 30, male: 68) participated in this study. The CRF was measured using a gas analyzer on a treadmill and physical fitness included body mass index, sit-up in one minute, standing long jump, sit-and-reach, 800 (female) and 1600-m (male) run/walk. The two assessments were scheduled by an interval of $7-10$ days. The grade point average (GPA) in formal grade report was provided by each participant after the completion of the first academic year. The data were analyzed by an independent $\mathrm{t}$-test and the relationships between variables were analyzed by Pearson product-moment correlation. The results displayed that males were significantly higher than females in CRF $(p<0.05)$. For physical fitness, the BMI, sit-up in one minute, standing long jump were significantly higher in males than in females. However, females were significantly higher than males in the number of sit-and-reach $(p<0.05)$. For academic performance, the GPA displayed similar between different genders. After regression analyses, the CRF was significantly related with academic performance and explained $56 \%$ of the variance for GPA in male college freshmen. However, neither CRF nor the components of physical fitness showed any significant relationship with academic performance in females. In conclusion, the CRF accounted for the variance of academic performance in male. However, a similar result was not found in the female part.
\end{abstract}

\section{Keywords}

Maximal Oxygen Consumption, Grade Point Average, Running Performance 


\section{Introduction}

Many college students face physiological, psychological and environmental challenges during the first year in college because of the transition from adolescence to adulthood (Dyson \& Renk, 2006). In addition, learning and study demanding during college were different from those during senior high school. Of the changes in physiology and physique, the alteration in body weight should be alert. The study (Butler, Black, Blue, \& Gretebeck, 2004) indicated that although the changes in physical activity and food intake occurred during the period of the first year in college, a decrease in physical activity was the main factor for an increase in body weight. On the other hand, physical inactivity or sedentary lifestyle is one of important contributors to lower cardiorespiratory fitness (Armstrong et al., 2006), which is associated with many diseases, such as hypertension, insulin resistance, and stroke (Healy, Matthews, Dunstan, Winkler, \& Owen, 2011; Wilmot et al., 2012). Therefore, the issues of cardiorespiratory fitness and physical activity are important for college students.

In general, cardiorespiratory fitness $(\mathrm{CRF})$ is measured using individual's maximum rate of oxygen consumption $\left(\mathrm{VO}_{2} \mathrm{max}\right)$ during incremental exercise. In addition to being in association with physical activity, CRF was also significantly positively related with cognition (Åberg et al., 2009; Voss et al., 2011). Furthermore, the improvement in cognitive capacity was related with the enhancement in CRF by physical activity or exercise intervention in healthy elders or those with mild cognitive impairment (Reiter et al., 2015; Smith et al., 2013; Voss et al., 2013). There were several possible factors for the improvement of cognition due to the intervention of exercise, such as an increase in cortical thickness (Reiter et al., 2015), maintenance or improvement of brain function and structure (Burzynska et al., 2014; Colcombe et al., 2006), and an increase in brain blood flow (Burdette et al., 2010) although further studies are warranted for precise mechanisms. Recent studies indicated (De Almeida Santana et al., 2017; García-Hermoso, Esteban-Cornejo, Olloquequi, \& Ramírez-Vélez, 2017) that CRF was significantly related with academic performance in children and young teenagers.

One recent study (Hôtting \& Röder, 2013) indicated that low physical fitness might negatively affect academic learning in college-aged women. It was possible that poor academic learning resulted in lower academic performance. Currently, many studies have investigated the effect of health-related physical fitness on academic performance in children and adolescents. The results showed that the improvement in academic performance was associated with the elevation of physical fitness due to the intervention of exercise, in addition to a significant relationship between academic performance and physical fitness (Blom, Alvarez, Zhang, \& Kolbo, 2011; De Greeff et al., 2014; Van Dusen, Kelder, Kohl, Ranjit, \& Perry, 2011; Welk et al., 2010). Taken the above-mentioned studies collectively, although many studies have examined the association between CRF and academic performance and the effect of CRF via exercise intervention on academic performance of children and teenagers, there are few studies exploring college stu- 
dents in similar aspects. As a result, the aim of this study was to examine the association between CRF and academic performance in college freshmen. Based on significant associations between academic performance and CRF and physical fitness in children and adolescents, the hypothesis of this study was that a significant relationship between CRF and academic performance existed in college freshmen.

\section{Methods}

\subsection{Participants}

This study was approved by the institutional review board of local hospital (An Tai Hospital, Pingtung). The information of inviting participants was announced in the bullet boards of campus activities. The criteria of inclusion were as follows: possible participants were enrolled in the first year of undergraduate college, but they were not the member of any college or club sport team. No cardiometabolic or muscuoskeleton disease was diagnosed. In addition, those who smoke or have alcohol use habit were excluded in this study. There were 110 (37 females/73 males) expressing their interest in this research. The participants and their legal guardians provided their written consent before enrolling in this study.

\subsection{Health-Related Physical Fitness}

Body mass index

The height and body mass of all participants were measured using wall-mounted tape measures and electronic scales, respectively. All participants were barefoot and dressed in swimming suit during measurements. The body mass index (BMI) was calculated as body mass $(\mathrm{kg})$ divided by height squared $\left(\mathrm{m}^{2}\right)$.

Sit-up in one minute

The number of sit-up in one-minute was used for assessing the muscular strength. Each participant lay on a mat with crossed their arms placing on their chest. In addition, the participant bent their knees with personal comfortable angle. When they conducted this test, one assistant maintained the participant's feet firmly on the ground. The standard sit-up was that the participant must touch their knees using their elbows and return his/her back on the ground. The assistant counted the number of sit-up the participant completed.

Standing long jump

The standing long jump was the representative of explosive strength of the lower body. Each participant stood behind the starting line with their feet approximately personal shoulder width and jumped horizontally as far as he/she could. When jumping, the participant must take off and land with two feet together. The jump distance was recorded by centimeter using a tape ruler.

Sit-and-reach

The sit-and-reach was assessed for the lower-extremity flexibility. Before measuring, each participant sat on the floor with their legs fully extended and the ruler was placed between the two legs. Next, the participant was asked to slowly 
reach as far as they could on the ruler using the fingertip of overlapped palms for two seconds while measuring. Three trials were performed and the best result was recorded.

800 and $1600-\mathrm{m}$ run/walk

The 800 and $1600-\mathrm{m}$ run/walk were measured in female and male participants, respectively. All participants were instructed to complete as fast as they could. If they were unable to run in all procedure, they were allowed to walk. The measurement was performed in a standard 400-m running track of athletic field. The completion time was measured in minutes and seconds by a stopwatch (Seiko, Japan).

\subsection{Cardiorespiratory Fitness}

Maximal oxygen consumption $\left(\mathrm{VO}_{2} \mathrm{max}\right)$ was the representative of cardiorespiratory fitness (CRF) in this study. All participants' $\mathrm{VO}_{2} \max$ were measured using MasterScreen CPX (Carefusion, Hoechberg, Germany) on a treadmill (T8000, Johnson, Taiwan). Before the $\mathrm{VO}_{2}$ max measurement, the participant had a 3-min walk at $5.5 \mathrm{~km}$ per hour on the treadmill. The speed was $6 \mathrm{~km} / \mathrm{h}$ at the beginning and increased to $12 \mathrm{~km}$ per by $1 \mathrm{~km} / \mathrm{hr}$ each minute. And, the speed maintained at $12 \mathrm{~km} / \mathrm{hr}$, but the slope increased by $2 \%$ grade each minute from the $0 \%$ until the criteria of maximum oxygen consumption. The maximal oxygen consumption was considered to be achieved if two of the following criteria were met: 1) heart rate (HR): age-predicted maximal HR (220-age) (Polar, Vantage XL Polar System, Port Washington, NY); 2) respiratory exchange ratio (RER, RER $\left.=\mathrm{VCO}_{2} / \mathrm{VO}_{2}\right)>$ $1.05 ; 3)$ rate perceived exhaustion $>17$ (RPE, Borg, 1982).

\subsection{Grade Point Average}

The grade point average (GPA) of each college freshman student was displayed in his/her annual academic report. After the end of the first year, the participant provided his/her formal academic report issued by the university. The range of GPA was from 0 to 4.3 .

\subsection{Data Analysis}

The data were collected and analyzed when the participant completed all assessments and the whole academic year. All data were expressed as mean \pm standard (SD) and evaluated the normality by Shapiro-Wilk. The variables between different genders were analyzed by an independent student's t-test. The association between GPA and CRF and the components of physical fitness were assessed separately for males and females by Pearson product-moment correlation. The significance was accepted at a level of $p<0.05$.

\section{Results}

A total of 98 participants (female: 30, male: 68) completed all measurements and their first academic year in this study. Five male and seven female college stu- 
dents did not complete CRF, physical fitness or whole academic year due to their personal reasons. Table 1 shows the CRF and health-related physical fitness of male and female participants. Due to different distances $(800 / 1600 \mathrm{~m})$ between different genders, the time to complete the distance was significantly longer in male participants than in female participants. However, male participants were faster than female counterparts in terms of the average speed ( $2.90 \pm 0.4$ vs. 2.85 $\pm 0.3 \mathrm{~m} / \mathrm{s}$ ) despite no significant difference between them. For other physical fitness components, male participants were significantly higher female participants in BMI, bent-leg sit-up in one minute, standing long jump; however, female participants showed significantly higher than male participants in sit-and-reach. Regarding CRF, the $\mathrm{VO}_{2}$ max was significantly higher in male than in female participants (Table 1). For GPA, male and female participants were 3.6 \pm 0.3 and $3.7 \pm 0.2$, respectively, without a significant difference between them.

For the association between academic performance and CRF, there was a significant relationship between GPA and CRF in male freshmen ( $r=0.77, p=0.00$, Figure 1). In addition, the time to complete $1600 \mathrm{~m}$ of health-related physical fitness was also significantly related to the GPA in male participants $(r=-0.63, p$ $=0.00$ ). However, the other components, BMI, bent-leg sit-up in one minute, standing long jump or sit-and-reach, did not significantly relate with GPA in male. For female freshmen, GPA did not correlate with CRF or the components of health-related physical fitness.

After further regression analyses, the CRF accounted for $56 \%$ of the variance in GPA in male participants. The components of health-related physical fitness did not account for the variance of GPA in male or in female participants. Therefore, CRF was only one predictor for academic performance in male participants among all measured variables.

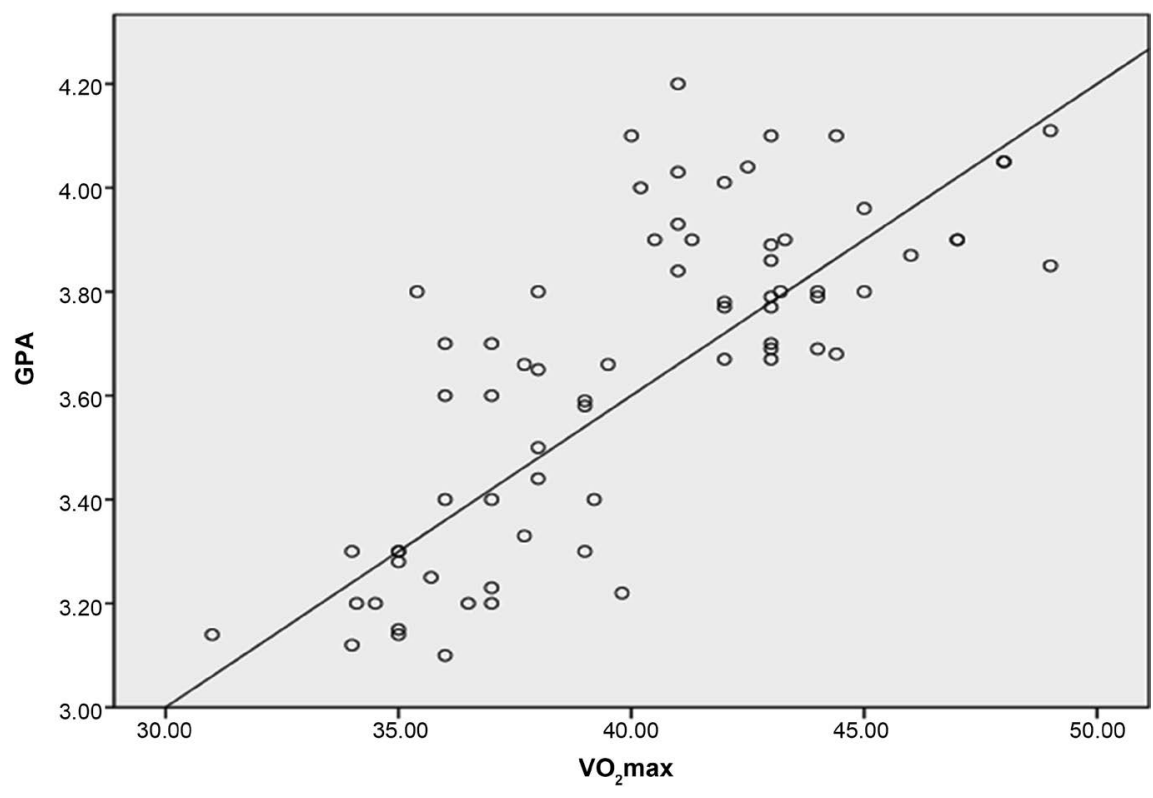

Figure 1. The relationship between academic performance (GPA) and cardiorespiratory fitness $\left(\mathrm{VO}_{2} \mathrm{max}\right)$ in male college first-year students. 
Table 1. The participants' health-related physical fitness and cardiorespiratory fitness.

\begin{tabular}{|c|c|c|c|}
\hline & Male $(\mathrm{n}=68)$ & Female $(\mathrm{n}=30)$ & t value \\
\hline Body mass index $\left(\mathrm{kg} / \mathrm{m}^{2}\right)$ & $22.2 \pm 2.8$ & $19.3 \pm 2.7$ & $<0.05$ \\
\hline Sit-and-reach ${ }^{*}(\mathrm{~cm})$ & $26.8 \pm 10.2$ & $32.8 \pm 10.5$ & $<0.05$ \\
\hline Standing long jump* $(\mathrm{cm})$ & $205.7 \pm 24.6$ & $151.3 \pm 18.6$ & $<0.05$ \\
\hline Sit-up ${ }^{*}($ times $/ \mathrm{min})$ & $40.9 \pm 8.5$ & $28.2 \pm 9.2$ & $<0.05$ \\
\hline $1600 / 800 \mathrm{run} /$ walk $^{*}(\mathrm{sec})$ & $513.4 \pm 69.6$ & $271.3 \pm 27.7$ & $<0.05$ \\
\hline $\mathrm{CRF}^{\star}(\mathrm{ml} / \mathrm{min} / \mathrm{kg})$ & $41.2 \pm 4.7$ & $37.1 \pm 3.6$ & $<0.05$ \\
\hline
\end{tabular}

*a significant difference between male and female; CRF: cardiorespiratory fitness.

\section{Discussion}

Many studies have examined the association between CRF and cognition in children and adolescents and a significant relationship was found between both of them. In the present study, the $\mathrm{VO}_{2}$ max is significantly correlated with academic performance in male college first-year students. For the components of physical fitness, the time to complete the 1600 -m correlates with GPA in male part as well. Although academic performance significantly correlated with cardiorespiratory fitness and physical fitness in children and adolescents and the study suggested that CRF was in association with a neurocognitive process which was integral for academic performance (Chu, Chen, Pontifex, Sun, \& Chang, 2016), similar issues concerning college students have been barely explored. Therefore, the result of this study adds the evidence to the relevant fields in terms of different participants.

The result regarding a significant association between CRF and academic performance in male college first-year students was the same as the other studies, which examined the same two variables in children (De Almeida Santana et al., 2017) and adolescents (García-Hermoso, Esteban-Cornejo, Olloquequi, \& Ramírez-Vélez, 2017; Kwak et al., 2009). In addition, the CRF was the main explanatory factor for the GPA in male college participants after further regression. Although the mechanisms regarding CRF affecting academic performance have not been elucidated clearly, a few findings might account for the association between them. One study indicated that CRF was positively related with main neurocognitive process which was integral to academic performance (Chen, Fox, $\mathrm{Ku}$, \& Taun, 2013). Furthermore, the improvement in cognition due to exercise intervention might contribute to an enhancement in academic performance of children and young adolescents (Chaddock-Heyman, Hillman, Cohen, \& Kramer, 2014; Hillman et al., 2014; Leckie et al., 2014). Cognition plays an important role in learning and academic performance. Based on the above-mentioned studies, this study inferred that cognition might be a bridge between CRF and academic performance. Therefore, further research on the mechanisms for CRF affecting academic performance via cognition is warranted. In spite of a significant association between CRF and academic performance similar to previous studies examining 
the same two variables, several obvious differences in methodologies between this and previous studies worth noting such as using the developed formulas (PACER) to estimate cardiorespiratory fitness and mathematics and reading examinations given to students without prior notice to represent academic performance in previous studies.

For the relationship between academic performance and the components of physical fitness in the current study, the time to complete a $1600-\mathrm{m}$ was significantly associated with academic performance in male participants. In the aspect of physical fitness and academic performance, there were fewer studies for college students compared with similar studies for children and adolescents; however, the time to complete a $1600-\mathrm{m}$ in association with academic performance in this study was in line with the studies investigating the same variables in children (Chen, Fox, Ku, \& Taun, 2013; Van Dusen, Kelder, Kohl, Ranjit, \& Perry, 2011). Hillman, Castelli, \& Buck (2005) suggested that increased cerebral blood flow with higher neurotransmitter and oxygen in faster finishers might be responsible for the time to complete a given distance as fast as possible associating with academic performance; however, these factors were not measured in this study. On the other hand, a significant association between the time to complete $1600 \mathrm{~m}$ and CRF was worth extra attention. The studies (Burns et al., 2015; Pober, Freedson, Kline, McInnis, \& Rippe, 2002) indicated that the time to complete $1600 \mathrm{~m}$ was significantly negatively related with CRF. The studies indicated that higher-CRF individuals had higher neurocognitive function, shorter reaction time and more accurate response (Chaddock et al., 2010; Dupuy et al., 2015), which might benefit in elevating academic performance. In this study, a significant association between the time to complete a 1600-m and CRF was also found $(\mathrm{r}=-0.84, p<0.00)$, which implied faster finisher, higher CRF. On the basis of the finding, CRF relating to the time to complete a $1600-\mathrm{m}$ possibly indirectly led to a significant association between the time to complete a $1600-\mathrm{m}$ and academic performance. Therefore, further studies explore whether the factors for the relationship between academic performance and CRF may influence the relationship between academic performance and the time to complete a given distance of physical fitness at the same time.

In this study, except the time to complete the $1600-\mathrm{m}$, the other physical fitness components were not related with academic performance in males. Previous studies for children and teenagers displayed that some of physical fitness components were associated with academic performance, some were not (Castelli, Hillman, Buck, \& Erwin, 2007; Esteban-Cornejo et al., 2014; Eveland-Sayers et al., 2009; Kalantari \& Esmaeilzadeh, 2016). For example, body mass index (BMI). The studies (Castelli, Hillman, Buck, \& Erwin, 2007; Van Dusen, Kelder, Kohl, Ranjit, \& Perry, 2011) showed that BMI correlated with academic performance in children and juveniles, but, the other studies did not (Du Toit, Pienaar, \& Truter, 2011; London \& Castrechini, 2011; Wittberg, Northrup, \& Cottrel, 2009). In this study, there was no significant relationship between BMI and academic performance. On the other hand, academic performance was not related 
with CRF or the components of physical fitness in female participants. A few studies (Baxter, Guinn, Tebbs, \& Royer, 2013; Eveland-Sayers, Farley, Fuller, Morgan, \& Caputo, 2009) displayed similar results, some components of physical fitness relating with academic performance in males, but, the same components not relating with academic performance in females. Although the 800-m and 1600-m were an obvious difference between male and female participants, to explain factors resulting in different results between the genders was beyond the scope of this study.

The study (Butler, Black, Blue, \& Gretebeck, 2004) indicated that a decrease in physical activity led to an increase in body weight during the period of freshman. However, the engagement of physical activity and exercise can enhance cardiorespiratory fitness and shorten the time to complete a given distance at the same time (Eather, Morgan, \& Lubans, 2013; Kettunen, Vuorimaa, \& Vasankari, 2014; Singhal \& Siddhu, 2014). As a result, this study encourages college first-year students to participate more in aerobic physical activities or exercises, such as hiking, running, cycling and swimming, so that not only CRF but also academic performance may be elevated based on the finding regarding the association between CRF and GPA in this study.

A few limitations should be acknowledged in this study. With respect to cardiorespiratory fitness and academic performance, the participants in the majority of studies were children and teenagers. The studies examining the same variables for college freshmen are few. As a result, we can't help but refer to the studies regarding the effect of cardiorespiratory fitness and the components of physical fitness on academic performance and cognition of children, adolescents and senior adults. On the other hand, using whole year academic performance was also an obvious characteristic in this study, considering that the assessment of academic performance was different from the other studies which evaluated reading, language and mathematics without prior notice during the experiment. Grade point average (GPA) was based on all subjects learned by the participants during the first academic year. Therefore, the type of academic performance in this study was a long-term type, which was different from an impromptu type in the above-mentioned studies. Third, the sample size was smaller and the number of females was fewer compared with that of males in this study. On the basis of these limitations, it should be cautious when researchers generalized the current results to other populations.

\section{Conclusion}

$\mathrm{CRF}\left(\mathrm{VO}_{2} \mathrm{max}\right.$ ) and the time to complete the 1600 -m of physical fitness components were significantly related to the GPA in male college freshmen. Furthermore, $\mathrm{CRF}$ was the main predictor for their academic performance during the first year in college. Therefore, future studies for the reasons regarding why the CRF affects academic performance and whether the changes in CRF and physical fitness by the intervention of aerobic exercise are in association with the change in academic performance are necessary for college students. 


\section{Conflicts of Interest}

The authors declare no conflicts of interest regarding the publication of this paper.

\section{References}

Åberg, M. A., Pedersen, N. L., Torén, K., Svartengren, M., Bäckstrand, B., Johnsson, T., Kuhn, H. G. et al. (2009). Cardiovascular Fitness Is Associated with Cognition in Young Adulthood. Proceedings of the National Academy of Sciences of the United States of America, 106, 20906-20911. https://doi.org/10.1073/pnas.0905307106

Armstrong, K., Rakhit, D., Jeffriess, L., Johnson, D., Leano, R., Prins, J., Isbel, N. et al. (2006). Cardiorespiratory Fitness Is Related to Physical Inactivity, Metabolic Risk Factors, and Atherosclerotic Burden in Glucose-Intolerant Renal Transplant Recipients. Clinical Journal of the American Society Nephrology, 1, 1275-1283.

https://doi.org/10.2215/CJN.00210106

Baxter, S. D., Guinn, C. H., Tebbs, J. M., \& Royer, J. A. (2013). There Is No Relationship between Academic Achievement and Body Mass Index among Fourth-Grade, Predominantly African-American Children. Journal of the Academy of Nutrition and Dietetics, 113, 551-557. https://doi.org/10.1016/j.jand.2013.01.004

Blom, L. C., Alvarez, J., Zhang, L., \& Kolbo, J. (2011). Associations between Health-Related Physical Fitness, Academic Achievement and Selected Academic Behaviors of Elementary and Middle School Students in the State of Mississippi. Journal of Research in Health, Physical Education, Recreation, Sport \& Dance, 6, 13-19.

Borg, G. A. (1982). Psychophysical Bases of Perceived Exertion. Medicine and Science in Sports and Exercise, 14, 377-381. https://doi.org/10.1249/00005768-198205000-00012

Burdette, J. H., Laurienti, P. J., Espeland, M. A., Morgan, A., Telesford, Q., Vechlekar, C. D., Rejeski, W. J. et al. (2010). Using Network Science to Evaluate Exercise-Associated Brain Changes in Older Adults. Frontiers in Aging Neuroscience, 2, 23. https://doi.org/10.3389/fnagi.2010.00023

Burns, R. D., Hannon, J. C., Brusseau, T. A., Eisenman, P. A., Saint-Maurice, P. F., Welk, G. J., \& Mahar, M. T. (2015). Cross-Validation of Aerobic Capacity Prediction Models in Adolescents. Pediatric Exercise Science, 27, 404-411. https://doi.org/10.1123/pes.2014-0175

Burzynska, A. Z., Chaddock-Heyman, L., Voss, M. W., Wong, C. N., Gothe, N. P., Olson, E. A., Kramer, A. F. et al. (2014). Physical Activity and Cardiorespiratory Fitness Are Beneficial for White Matter in Low-Fit Older Adults. PLoS ONE, 9, e107413. https://doi.org/10.1371/journal.pone.0107413

Butler, S. M., Black, D. R., Blue, C. L., \& Gretebeck, R. J. (2004). Change in Diet, Physical Activity, and Body Weight in Female College Freshman. American Journal of Health Behavior, 8, 24-32. https://doi.org/10.5993/AJHB.28.1.3

Castelli, D. M., Hillman, C. H., Buck, S. M., \& Erwin, H. E. (2007). Physical Fitness and Academic Achievement in Third- and Fifth-Grade Students. Journal of Sport and EX ercise Psychology, 29, 239-252. https://doi.org/10.1123/jsep.29.2.239

Chaddock, L., Erickson, K. I., Prakash, R. S., Kim, J. S., Voss, M. W., Vanpatter, M., Kramer, A. F. et al. (2010). A Neuroimaging Investigation of the Association between Aerobic Fitness, Hippocampal Volume, and Memory Performance in Preadolescent Children. Brain Research, 1358, 172-183. https://doi.org/10.1016/j.brainres.2010.08.049

Chaddock-Heyman, L., Hillman, C. H., Cohen, N. J., \& Kramer, A. F. (2014). The Importance of Physical Activity and Aerobic Fitness for Cognitive Control and Memory in 
Children. Monographs of the Society for Research in Children Development, 79, 25-50. https://doi.org/10.1111/mono.12129

Chen, L. J., Fox, K. R., Ku, P. W., \& Taun, C. Y. (2013). Fitness Change and Subsequent Academic Performance in Adolescents. Journal of School Health, 83, 631-638. https://doi.org/10.1111/josh.12075

Chu, C. H., Chen, F. T., Pontifex, M. B., Sun, Y. L., \& Chang, Y. K. (2016). Health-Related Physical Fitness, Academic Achievement, and Neuroelectric Measures in Children and Adolescents. International Journal of Sport and Exercise Psychology, 17, 117-132.

Colcombe, S. J., Erickson, K. I., Scalf, P. E., Kim, J. S., Prakash, R., McAuley, E., Kramer, A. F. et al. (2006). Aerobic Exercise Training Increases Brain Volume in Aging Humans. The Journals of Gerontology. Series A, Biological Sciences and Medical Sciences, 61, 1166-1170. https://doi.org/10.1093/gerona/61.11.1166

De Almeida Santana, C. C., Farah, B. Q., de Azevedo, L. B., Hill, J. O., Gunnarsdottir, T., Botero, J. P., do Prado, W. L. et al. (2017). Associations between Cardiorespiratory Fitness and Overweight with Academic Performance in 12-Year-Old Brazilian Children. Pediatric Exercise Science, 29, 220-227. https://doi.org/10.1123/pes.2016-0048

De Greeff, J. W., Hartman, E., Mullender-Wijnsma, M. J., Bosker, R. J., Doolaard, S., \& Visscher, C. (2014). Physical Fitness and Academic Performance in Primary School Children with and without a Social Disadvantage. Health Education Research, 29, 853-860. https://doi.org/10.1093/her/cyu043

Du Toit, D., Pienaar, A. E., \& Truter, L. (2011). Relationship between Physical Fitness and Academic per Formance in South African Children. South African Journal for Research in Sport, Physical Education and Recreation, 33, 23-35.

Dupuy, O., Gauthier, C. J., Fraser, S. A. Desjardins-Crèpeau, L., Desjardins, M., Mekary, S., Bherer, L. et al. (2015) Higher Levels of Cardiovascular Fitness Are Associated with Better Executive Function and Prefrontal Oxygenation in Younger and Older Women. Frontier in Human Neuroscience, 9, Article 66. https://doi.org/10.3389/fnhum.2015.00066

Dyson, R., \& Renk, K. (2006). Freshmen Adaptation to University Life: Depressive Symptoms, Stress, and Coping. Journal of Clinical Psychology, 62, 1231-1244.

https://doi.org/10.1002/jclp.20295

Eather, N., Morgan, P. J., \& Lubans, D. R. (2013). Improving the Fitness and Physical Activity Levels of Primary School Children: Results of the Fit-4-Fun Group Randomized Controlled Trial. Preventive Medicine, 56, 12-19. https://doi.org/10.1016/j.ypmed.2012.10.019

Esteban-Cornejo, I., Terejo-Gonzalez, C. M., Martinez-Gomez, D., del-Campo, J., Gonzalez-Galo, A., Padilla-Moledo, C., \& Up Down Study Group (2014). Independent and Combined Influence of the Components of Physical Fitness on Academic Performance in Youth. The Journal Pediatrics, 165, 306-312.

https://doi.org/10.1016/j.jpeds.2014.04.044

Eveland-Sayers, B. M., Farley, R. S., Fuller, D. K., Morgan, D. W., \& Caputo, J. L. (2009). Physical Fitness and Academic Achievement in Elementary School Children. Journal of Physical Activity and Health, 6, 99-104. https://doi.org/10.1123/jpah.6.1.99

García-Hermoso, A., Esteban-Cornejo, I., Olloquequi, J., \& Ramírez-Vélez, R. (2017). Cardiorespiratory Fitness and Muscular Strength as Mediators of the Influence of Fatness on Academic Achievement. The Journal of Pediatrics, 187, 127-133. https://doi.org/10.1016/j.jpeds.2017.04.037

Healy, G. N., Matthews, C. E., Dunstan, D. W., Winkler, E. A., \& Owen, N. (2011). Sedentary Time and Cardio-Metabolic Biomarkers in US Adults: NHANES 2003-06. Eu- 
ropean Heart Journal, 32, 590-597. https://doi.org/10.1093/eurheartj/ehq451

Hillman, C. H., Castelli, D. M., \& Buck, S. M. (2005). Aerobic Fitness and Neurocognitive Function in Healthy Preadolescent Children. Medicine and Science in Sports and Exercise, 37, 1967-1974. https://doi.org/10.1249/01.mss.0000176680.79702.ce

Hillman, C. H., Pontifex, M. B., Castelli, D. M., Khan, N. A., Raine, L. B., Scudder, M. R., Kamijo, K. et al. (2014). Effects of the FIT Kids Randomized Controlled Trial on Executive Control and Brain Function. Pediatrics, 134, 1063-1071. https://doi.org/10.1542/peds.2013-3219

Hötting, K., \& Röder, B. (2013). Beneficial Effects of Physical Exercise on Neuroplasticity and Cognition. Neuroscience and Biobehavioral Reviews, 37, 2243-2257. https://doi.org/10.1016/j.neubiorev.2013.04.005

Kalantari, H. A., \& Esmaeilzadeh, S. (2016). Association between Academic Achievement and Physical Status Including Physical Activity, Aerobic and Muscular Fitness Tests in Adolescent Boys. Environmental Health and Preventive Medicine, 21, 27-33. https://doi.org/10.1007/s12199-015-0495-X

Kettunen, O., Vuorimaa, T., \& Vasankari, T. (2014). 12-mo Intervention of Physical Exercise Improved Work Ability, Especially in Subjects with Low Baseline Work Ability. International Journal of Environmental Research and Public Health, 11, 3859-3869. https://doi.org/10.3390/ijerph110403859

Kwak, L., Kremers, S. P., Bergman, P., Ruiz, J. R., Rizzo, N. S., \& Sjöström, M. (2009). Associations between Physical Activity, Fitness, and Academic Achievement. The Journal of Pediatrics, 155, 914-918. https://doi.org/10.1016/j.jpeds.2009.06.019

Leckie, R. L., Oberlin, L. E., Voss, M. W., Prakash, R. S., Szabo-Reed, A., Chaddock-Heyman, L., Erickson, K. I. et al. (2014). BDNF Mediates Improvements in Executive Function Following a 1-Year Exercise Intervention. Frontiers in Human Neuroscience, 11, 985. https://doi.org/10.3389/fnhum.2014.00985

London, R. A., \& Castrechini, S. A. (2011). A Longitudinal Examination of the Link between Youth Physical Fitness and Academic Achievement. Journal of School Health, 81, 400-408. https://doi.org/10.1111/j.1746-1561.2011.00608.x

Pober, D. M., Freedson, P. S., Kline, G. M., McInnis, K. J., \& Rippe, J. M. (2002). Development and Validation of One-Mile Treadmill Walk Test to Predict Peak Oxygen Uptake in Healthy Adults Ages 40 to 79 Years. Canadian Journal of Applied Physiology, 27, 575-589. https://doi.org/10.1139/h02-033

Reiter, K., Nielson, K. A., Smith, T. J., Weiss, L. R., Alfini, A. J., \& Smith, J. C. (2015). Improved Cardiorespiratory Fitness Is Associated with Increased Cortical Thickness in Mild Cognitive Impairment. Journal of the International Neuropsychology Society, 21, 757-767. https://doi.org/10.1017/S135561771500079X

Singhal, N., \& Siddhu, A. (2014). Association of Leisure-Time Physical Activity with Cardiorespiratory Fitness in Indian Men. Journal of Physical Activity and Health, 11, 296-302. https://doi.org/10.1123/jpah.2012-0029

Smith, J. C., Nielson, K. A., Antuono, P., Lyons, J. A., Hanson, R. J., Butts, A. M., \& Verber, M. D. (2013). Semantic Memory Functional MRI and Cognitive Function after Exercise Intervention in Mild Cognitive Impairment. Journal of Alzheimer's Disease, 37, 197-215. https://doi.org/10.3233/JAD-130467

Van Dusen, D. P., Kelder, S. H., Kohl, H. W., Ranjit, N., \& Perry, C. L. (2011). Associations of Physical Fitness and Academic Performance among Schoolchildren. Journal of School Health, 81, 733-740. https://doi.org/10.1111/j.1746-1561.2011.00652.x

Voss, M. W., Chaddock, L., Kim, J. S., Vanpatter, M., Pontifex, M. B., Raine, L. B., Kramer, A. F. et al. (2011). Aerobic Fitness Is Associated with Greater Efficiency of the 
Network Underlying Cognitive Control in Preadolescent Children. Neuroscience, 199, 166-176. https://doi.org/10.1016/j.neuroscience.2011.10.009

Voss, M. W., Heo, S., Prakash, S., Erickson, K. I., Alves, H., Chaddock, L., Kramer, A. F. et al. (2013). The Influence of Aerobic Fitness on Cerebral White Matter Integrity and Cognitive Function in Older Adults: Results of a One-Year Exercise Intervention. $\mathrm{Hu}$ man Brain Mapping, 34, 2972-2985. https://doi.org/10.1002/hbm.22119

Welk, G. J., Jackson, A. W., Morrow, J. R. Jr., Haskell, W. H., Meredith, M. D., \& Cooper, K. H. (2010). The Association of Health-Related Fitness with Indicators of Academic Performance in Texas Schools. Research Quarterly for Exercise and Sport, 81, S16-S23. https://doi.org/10.5641/027013610X13100547898031

Wilmot, E. G., Edwardson, C. L., Achana, F. A., Davies, M. J., Gorely, T., Gray, L. J., Biddle, S. J. et al. (2012). Sedentary Time in Adults and the Association with Diabetes, Cardiovascular Disease and Death: Systematic Review and Meta-Analysis. Diabetolo gia, 55, 2895-2905. https://doi.org/10.1007/s00125-012-2677-Z

Wittberg, R. A., Northrup, K. L., \& Cottrel, L. (2009). Children's Physical Fitness and Academic Performance. American Journal of Health Education, 40, 30-36.

https://doi.org/10.1080/19325037.2009.10599076 